\title{
Essai de gobetage des mycéliums de Pleurotus cystidiosus à Kinshasa en R.D. Congo
}

\author{
Serge KABAMBA ${ }^{1 *}$, Gregory NZEMOTI ${ }^{1}$ et Victorine MBADU ${ }^{1,2}$ \\ ${ }^{1}$ Université Loyola du Congo (ULC), Faculté des Sciences Agronomiques et Vétérinaires (FSAV), Gestion des \\ Ressources Naturelles Renouvelables. BP 3724 Kinshasa Gombe, R.D. Congo. \\ ${ }_{2}^{2}$ Institut Supérieur des Techniques Médicales/Kinshasa, Section des Techniques de Laboratoire \\ (ISTM/Kinshasa), R.D. Congo. \\ *Auteur correspondant ; E-mail : herslix@gmail.com, Tél : +243 824970684.
}

\author{
Received: 22-12-2020
}

Accepted: $27-04-2021$

Published: 30-04-2021

\section{RESUME}

Il a été montré que les fortes pluies et chaleurs réduisaient les rendements du Pleurotus cystidiosus. La présente étude visait à trouver une méthode de culture pouvant limiter les chutes de rendement de Pleurotus cystidiosus en saisons humides et chaudes. Deux techniques à savoir celle de la culture sur étagère et du gobetage ont été utilisées comme traitement appliqué chacun à un échantillon de 30 sachets de substrat ensemencé. Les moyennes des températures étaient de $28,2{ }^{\circ} \mathrm{C}$ pour la saison des pluies et de $25,5{ }^{\circ} \mathrm{C}$ pour la saison sèche L'analyse de la variance a révélé une différence hautement significative $(p \leq 0,0000)$ entre le rendement obtenu avec la culture à l'étagère et celui obtenu avec le gobetage. Cette différence n'a été constatée que pendant la période des fortes chaleurs. Les moyennes des rendements sont respectivement de 378,8 $\pm 39,5 \mathrm{~g}$ en saison de pluies et de $474,3 \mathrm{~g} \pm 50,1 \mathrm{~g}$ en saison sèche pour la culture à l'étagère et $638,7 \pm 64,8 \mathrm{~g}$ en saison des pluies et $531,3 \pm 94,03 \mathrm{~g}$ en saison sèche pour le gobetage. Donc, le gobetage peut sauvegarder le rendement de Pleurotus cystidiosus pendant les périodes de fortes pluies et les plus chaudes de l'année.

(C) 2021 International Formulae Group. All rights reserved.

Mots clés : Myciculture, rendement, température, substrat, pleurote.

\section{Casing test of Pleurotus cystidiosus mycelia in Kinshasa in D.R. Congo}

\begin{abstract}
Heavy rains and heat have been shown to reduce the yields of Pleurotus cystidiosus. The aim of this study was to find an appropriate method to cultivate Pleurotus cystidiosus by preventing its fall in yield during high temperatures season of the year. Two techniques, namely that of the cultivation on the shelf and the casing, were used as treatment each applied to a sample of 30 bags of inoculated substrate. The average temperatures were $28.2{ }^{\circ} \mathrm{C}$ for the rainy season and $25.5{ }^{\circ} \mathrm{C}$ for the dry season. Analysis of variance revealed a highly significant difference $(\mathrm{p} \leq 0.0000)$ between the yield obtained with the culture on the shelf and that obtained with the casing. This difference was only seen during the hot weather. The average yields were respectively $378.8 \pm$ $39.5 \mathrm{~g}$ in the rainy season and $474.3 \mathrm{~g} \pm 50.1 \mathrm{~g}$ in the dry season for shelf cultivation and $638.7 \pm 64.8 \mathrm{~g}$ in the rainy season and $531.3 \pm 94.03 \mathrm{~g}$ in the dry season for casing. These results suggest that casing can safeguard the yield of Pleurotus cystidiosus during the hottest periods of the year.
\end{abstract}

(C) 2021 International Formulae Group. All rights reserved.

Keywords: Myciculture, yield, temperature, substrate, pleurotus. 


\section{INTRODUCTION}

L'importance des produits forestiers non ligneux (PFNL) n'est plus à démontrer dans les forêts tropicales et subtropicales, situées particulièrement en Afrique, en Asie et en Amérique Latine. Ces produits complètent la production agricole des ménages en leur fournissant de la nourriture, des médicaments, du fourrage, de la paille, etc. Ils sont des bouées de sauvetage en aliments pendant la période de soudure et constituent un maillon de sécurité alimentaire d'urgence contre des aléas saisonniers et en cas de nécessité urgente pour les ménages (Mukenji 1995, cité par Loubelo 2012)

Les champignons comestibles, partie intégrante des PFNL, sont largement répandus dans le monde et, sont des aliments riches en vitamines B1, B2, B3 (Eil, 1994) et en protéines (Verfaillie, 1983), appréciés des populations rurales (Bram et Janna, 2007).

En Afrique centrale en général et en République Démocratique du Congo (RD Congo) en particulier, ils constituent un des PFNL d'une importance non négligeable tant du point de vue nutritionnel qu'économique (Ndoye et al., 2007), car en effet, la myciculture est une très bonne source de revenus. Cependant lors de la saison des pluies, la température extérieure, souvent élevée, dépasse généralement la température seuil (30 ${ }^{\circ} \mathrm{C}$ ) pour une bonne croissance et une bonne fructification des champignons. Cela a très souvent un impact négatif sur le rendement. Il tient lieu de signaler qu'en matière de rendement, certaines espèces de Pleurotus produisent des rendements très élevés en quelques semaines, ces champignons peuvent convertir $100 \mathrm{~g}$ de matières végétales à déchets secs en 50 à $70 \mathrm{~g}$ de champignons Pleurotus frais (Lelly, 1987). La culture est alors interrompue pendant cette période du fait que les myciculteurs n'arrivent pas à contrôler suffisamment la température ambiante (Eil, 2005).

La technique du gobetage qui consiste à recouvrir avec de la terre, un substrat déjà colonisé par le mycélium, procure les microorganismes indispensables et le taux d'humidité nécessaire pour inciter le mycélium à produire une bonne récolte. Il sert aussi de régulation de l'humidité (Bram et Janna, 2007). $\mathrm{Au}$ regard de ce qui précède, le gobetage pourrait être une solution idoine à ce problème que connaît notre pays, la RD Congo, pour la culture des champignons en général et du pleurote en particulier. Ainsi, la présente étude avait donc pour objectif d'essayer la technique de gobetage comme moyen de sauvegarde du rendement de la culture du pleurote pendant toute l'année.

\section{MATERIEL ET METHODES Milieu}

Les expérimentations ont été réalisées à Kinshasa, en République Démocratique du Congo, à la résidence du foyer Universitaire Saint-Paul (4²3'40's et $15^{\circ} 18^{\prime} 39,9^{\prime}$ '). Cette étude a été menée en 2 essais différents : 1'un à l'intérieur d'une salle servant habituellement à la myciculture (champignonnière) et l'autre dans une serre en tunnel construite avec des matériaux trouvés localement. La serre a été placée dans un sous-bois.

Durant l'étude, la température a été prélevée avec un thermomètre-hygromètre placé dans la champignonnière et dans la serre. La température maximale moyenne observée durant la saison sèche était de $27,3^{\circ} \mathrm{C}$, tandis qu'en saison de pluie, elle était de $33,3{ }^{\circ} \mathrm{C}$. Cette température moyenne maximale du mois de mars $\left(33,3{ }^{\circ} \mathrm{C}\right)$ dépasse la température maximale favorable à une bonne fructification de l'espèce Pleurotus cystidiosus. En saison de pluies, la température minimale moyenne était de $26,8^{\circ} \mathrm{C}$, tandis qu'en saison sèche, elle était de $17,7^{\circ} \mathrm{C}$. Cette dernière constitue de nouveau une contrainte pour Pleurotus cystidiosus. En effet d'après Eil (2005), l'intervalle de température favorable à la croissance mycélienne de Pleurotus cystidiosus se situe entre 25 et $28{ }^{\circ} \mathrm{C}$; celle optimale pour la fructification de son mycélium se situe entre 25 et $30^{\circ} \mathrm{C}$. 


\section{Matériel}

Pleurotus cystidiosus a été utilisé comme matériel mycicole. Les champignons $\mathrm{du}$ genre Pleurotus appartiennent à l'embranchement de Basidiomycètes, à l'ordre des Agaricales et à la famille des Pleurotaceae (Pegler, 1980). Le substrat utilisé était constitué d'un mélange des copeaux et sciures de bois (78\%), du son de blé (20\%) et de la chaux éteinte (2\%).

\section{Méthodes}

\section{Trempage et égouttage}

Avant de faire le mélange, le substrat a été trempé dans l'eau pendant au moins 24 heures puis ressorti pour être égoutté. Le test d'essorage a été fait afin de confirmer la réussite de l'égouttage. Ce test consiste à presser par le poignet une partie de substrat. S'il y a des gouttes d'eau qui sortent, il faut continuer à égoutter afin d'éliminer l'excès d'eau.

\section{Mélange}

Pour enrichir le milieu en éléments nutritifs, le son de blé a été ajouté à un mélange des copeaux et sciures de bois. La chaux éteinte incorporée à ce mélange avait pour but de corriger le $\mathrm{pH}$ à l'intérieur du substrat. Après avoir fait le mélange, le $\mathrm{pH}$ du substrat mesuré à l'aide d'un papier pH-mètre était de 6,5. La formule utilisée lors de l'expérimentation était celle d'Eil (2005) (Tableau 1). Elle était majoritairement composée de copeaux et sciures de bois soit $78 \%$.

\section{Ensachage}

L'ensachage a consisté à placer le mélange dans des sachets thermorésistants. L'entassement a été moins fort pour éviter l'asphyxie du mycélium et ne pas donner un grand travail au mycélium lors de la colonisation des substrats. Chaque sachet a été fermé à l'aide d'un anneau en plastique et une partie d'éponge.

\section{Pasteurisation}

Un fut vide avec résistance a été utilisé pour chauffer et pasteuriser les substrats avec les bois de chauffage comme source d'énergie.
La température de la pasteurisation était de 82 ${ }^{\circ} \mathrm{C}$. Elle a été prélevée à l'aide d'un thermomètre pour stérilisateur. Au fond, audessus de la quantité d'eau mise dans le fût, un treillis a été mis pour empêcher un contact direct de l'eau avec les sacs des substrats. 20 litres d'eau ont été mis pour une durée de pasteurisation de 4 heures.

\section{Lardage}

Le lardage a consisté à mettre la semence du champignon (blanc de semis) dans le substrat préparé pour la pousse des champignons. Pour ce faire, deux cuillérées à soupe de blanc de semis ont été mis dans le sachet contenant le substrat. L'ensemencement des substrats à l'intérieur d'une caisse d'inoculation (Figure 1) s'est réalisé dans des conditions aseptiques à côté de la flamme d'une lampe à alcool. Il s'est fait à raison de deux cuillerées à soupe de semences ou blanc de semis dans un sachet contenant $1 \mathrm{~kg}$ de substrat. Après cette opération, le sachet a été fermé avec une éponge entouré d'un anneau. L'alcool éthylique a aussi été utilisé pour la désinfection des ustensiles. Les substrats ensemencés ont été gardés dans une salle d'incubation jusqu'à leur colonisation totale par des filaments du mycélium. Deux manières de la méthode d'Cil (1994) ont été choisies pour l'expérimentation. Il s'agit de la technique de culture en tranchées ou gobetage dans la serre et de celle sur étagère dans la champignonnière.

\section{Gobetage}

La préparation du terrain pour la culture en tranchées a consisté à aménager une tranchée de $3 \mathrm{~m}$ de long, $30 \mathrm{~cm}$ de large et 35 $\mathrm{cm}$ de profondeur, à mélanger de façon homogène de la terre propre avec du calcaire et à placer au fond de la tranchée un film plastique pour éviter les termites. Le sachet sur les substrats colonisés a été enlevé à l'aide d'une lame de rasoir. Les substrats ont ensuite été enfouis en position debout les uns aux côtés des autres. Le tout a été couvert avec une couche de terre d'environ 2 à $3 \mathrm{~cm}$ d'épaisseur arrosée avec un peu d'eau 1 à 2 fois par jour en fonction 
des conditions climatiques. L'arrosage dans la champignonnière s'est fait avec le même rythme que dans la serre.

\section{Culture sur les étagères}

Quant à la technique sur les étagères, les sachets sont troués pour permettre le passage des primordia, puis déposés sur des étagères en bois.

\section{Dispositif expérimental}

Le dispositif expérimental utilisé était le bloc complet randomisé et le seul facteur à l'étude était la technique de fructification repartie en deux traitements à savoir la technique de l'étagère et le gobetage. La champignonnière et la serre ont reçu chacune un échantillon de 30 sachets de substrat ensemencé. Le poids frais des champignons récoltés est le paramètre d'étude.

\section{Analyse statistique}

Les logiciels $\mathrm{R}$ et statistix 8.0 ont été utilisés pour l'analyse des données. Les données de mesure ont été soumises à l'analyse de la variance au seuil de signification de 0,05 sur base du dispositif en bloc complet randomisé.

Tableau 1: Proportion en kg et \% du mélange de substrat définitif.

\begin{tabular}{lcc}
\hline Ingrédients & Quantité en kg & \% \\
\hline Substrat (copeaux et sciures de bois) & 78 & 78 \\
Son de blé & 20 & 20 \\
Chaux éteinte & 2 & 2 \\
\hline
\end{tabular}

Source : Eil, 2005

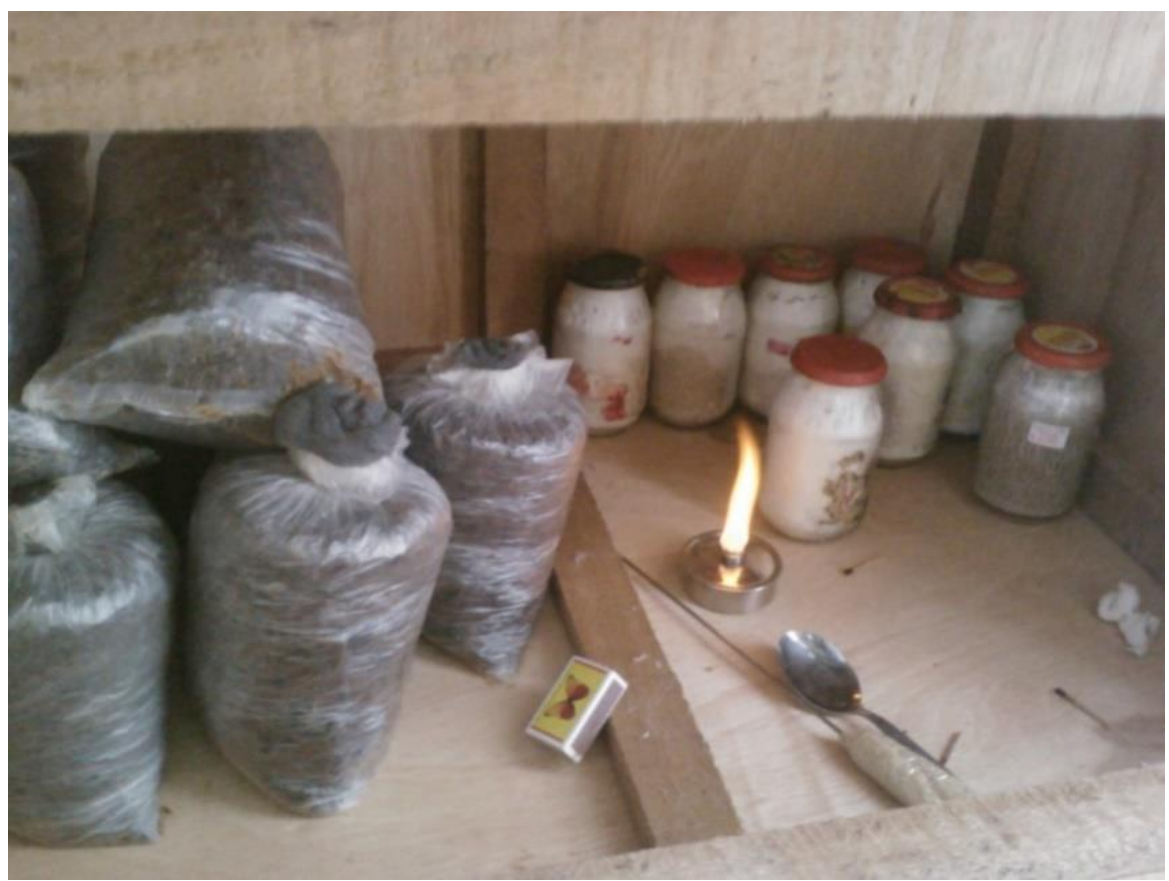

Figure 1 : La caisse d'inoculation. 


\section{RESULTATS}

\section{Rendement du champignon pendant la saison des pluies}

Il sied de noter que la technique de gobetage a donné un meilleur rendement avec un pic à la deuxième récolte $(237,8 \pm 70,6 \mathrm{~g})$ que la culture dans la champignonnière avec un pic à la $2^{\text {ième }}$ récolte $(106,17 \pm 20,1 \mathrm{~g})$ (Figure 2). L'analyse de la variance appliquée aux résultats de ces deux traitements en saison des pluies a montré une différence hautement significative $(p=0,0000)$.

\section{Rendement du champignon pendant la saison sèche}

En saison sèche, la technique de gobetage a encore donné un rendement légèrement meilleur avec un pic à la deuxième récolte $(169,3 \pm 61,6 \mathrm{~g})$ que la culture dans la champignonnière avec un pic à la $2^{\text {ième }}$ récolte $(143,3 \pm 48,6$ g) (Figure 3). L'analyse de la variance appliquée aux résultats de rendement des pleurotes en saison sèche n'a pas révélé une différence significative $(p=0,0514)$.

Il sied également de noter qu'après la quatrième récolte, le rendement a baissé sensiblement à tel point qu'on n'a récolté qu'une quantité variant entre $65,0 \pm 12,7 \mathrm{~g}$ en saison des pluies et $64,3 \pm 12,7 \mathrm{~g}$ en saison sèche pour le gobetage. En ce qui concerne la culture en champignonnière, la quantité récoltée variait entre $70,2 \pm 20,5 \mathrm{~g}$ en saison des pluies $70 \pm 14,6 \mathrm{~g}$ en saison sèche. La baisse graduelle $\mathrm{du}$ rendement résulte probablement de l'épuisement des nutriments dans les substrats par les mycéliums.

Le rendement des pleurotes par type de technique a été également considéré. En saison des pluies, la moyenne de production dans la champignonière a été plus faible qu'en saison saison sèche. C'est à la deuxième récolte qu'on a obtenu le meilleure rendement tandis qu'à la $4{ }^{\text {ième }}$ récolte, le rendement était le plus faible de tout (Figure 4). En ce qui concerne le gobetage, une récolte relativement bonne a été obtenue en saison des pluies. Mais, elle n'était pas très différentes pour les deux saisons (Figure 5). En définitive, la compraison de deux techniques a permis de noter des rendements très différents. Le Tableau 2 montre qu'en T0, $30 \mathrm{~kg}$ de substrat ont produit $11365 \mathrm{~g}(11,365 \mathrm{~kg})$ de champignon avec une moyenne de $378,833 \pm$ $39,516 \mathrm{~g}$ par kg de substrat tandis qu'en T1, $19160 \mathrm{~g}(19,160 \mathrm{~kg})$ de champignon sur $30 \mathrm{~kg}$ de substrat avec une moyenne de 638,667 \pm $64,793 \mathrm{~g}$ de champignon pour chaque substrat de $1 \mathrm{~kg}$. La plus-value $(\mathrm{p}=0,0000)$ montre que la différence entre ces deux traitements est hautement significative.

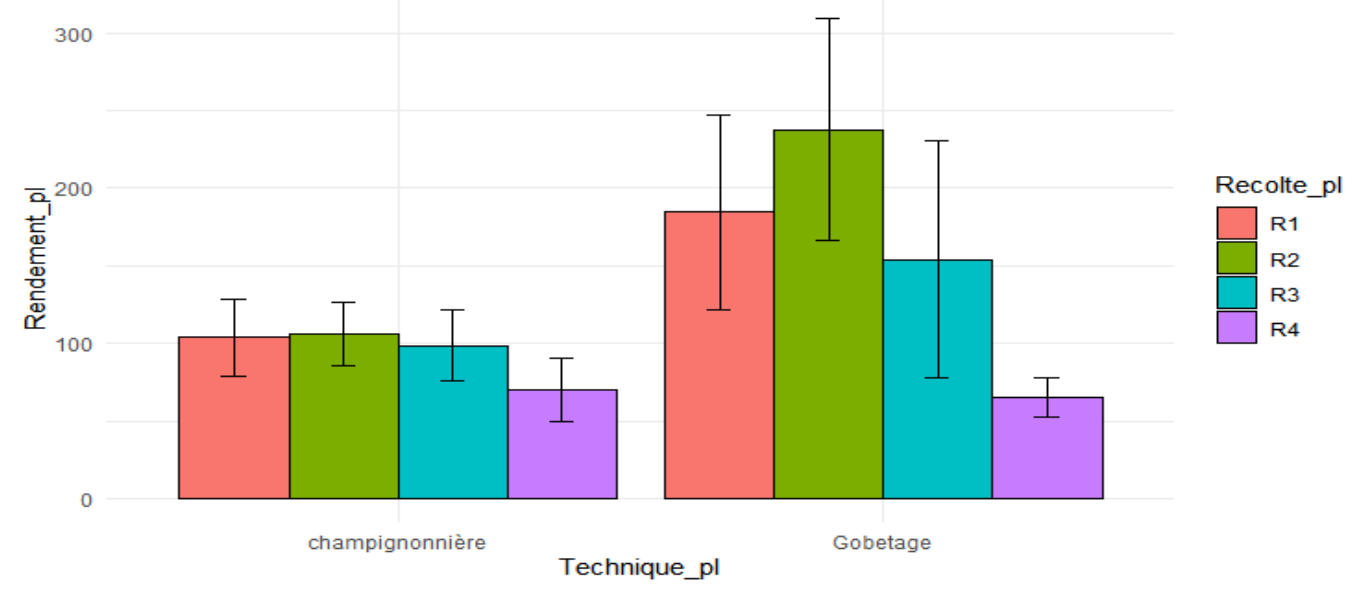

Légende : Rendement_pl : rendement en saison des pluies ; Technique_pl : technique utilisée en saison des pluies ; R1 : première récolte ; R2 : deuxième récolte ; R3 : troisième récolte ; R4 : quatrième récolte.

Figure 2 : Rendement en gr des Pleurotes selon les techniques de gobetage et de champignonnière durant la saison des pluies. 


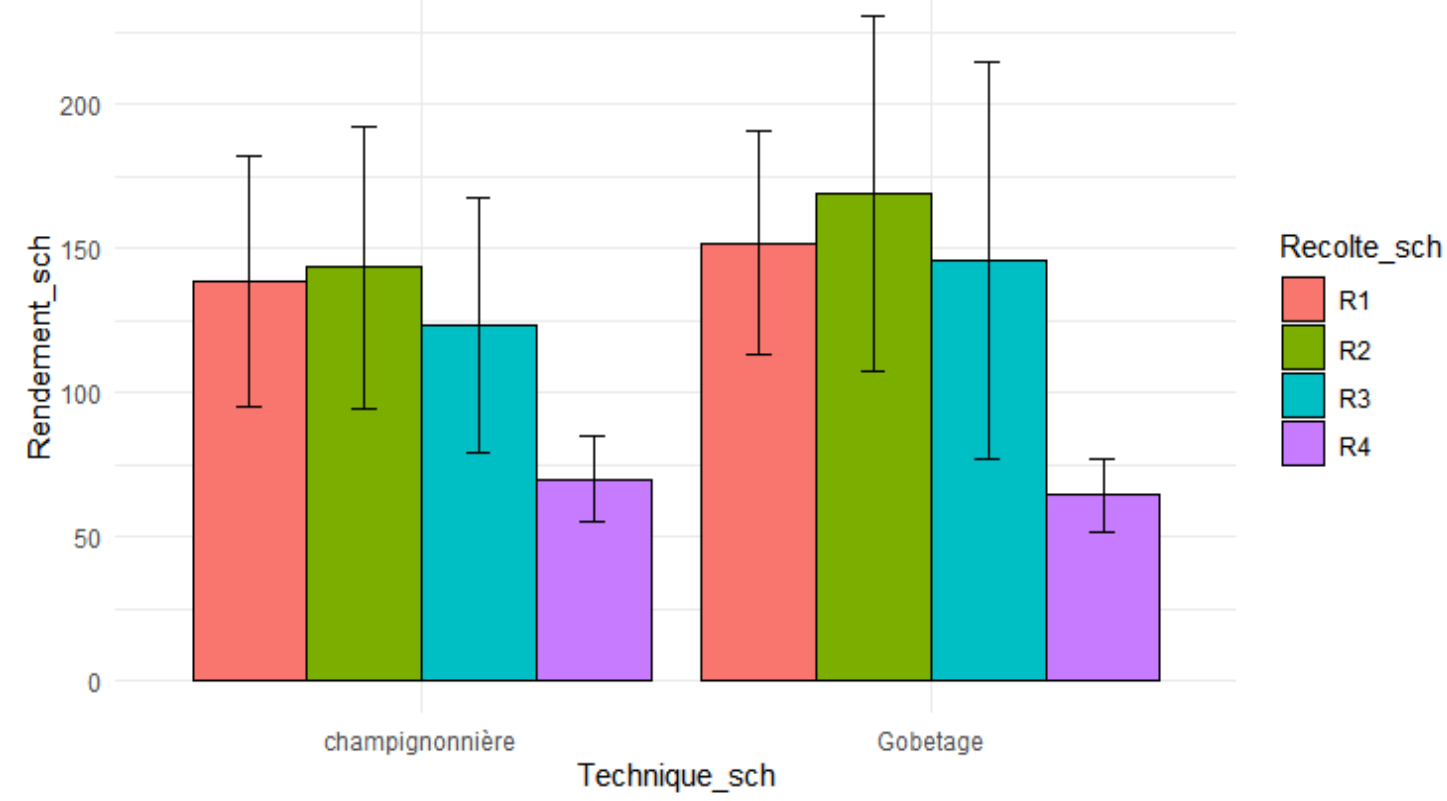

Légende : Rendement_sch : rendement en saison sèche ; Technique_sch : technique utilisée en saison sèche ; R1 : première récolte ; $\mathrm{R} 2$ : deuxième récolte $; \mathrm{R} 3$ : troisième récolte $; \mathrm{R} 4$ : quatrième récolte.

Figure 3 : Rendement en gr des Pleurotes selon les techniques de l'étagère dans la champignonnière et celle de gobetage dans la serre durant la saison sèche.

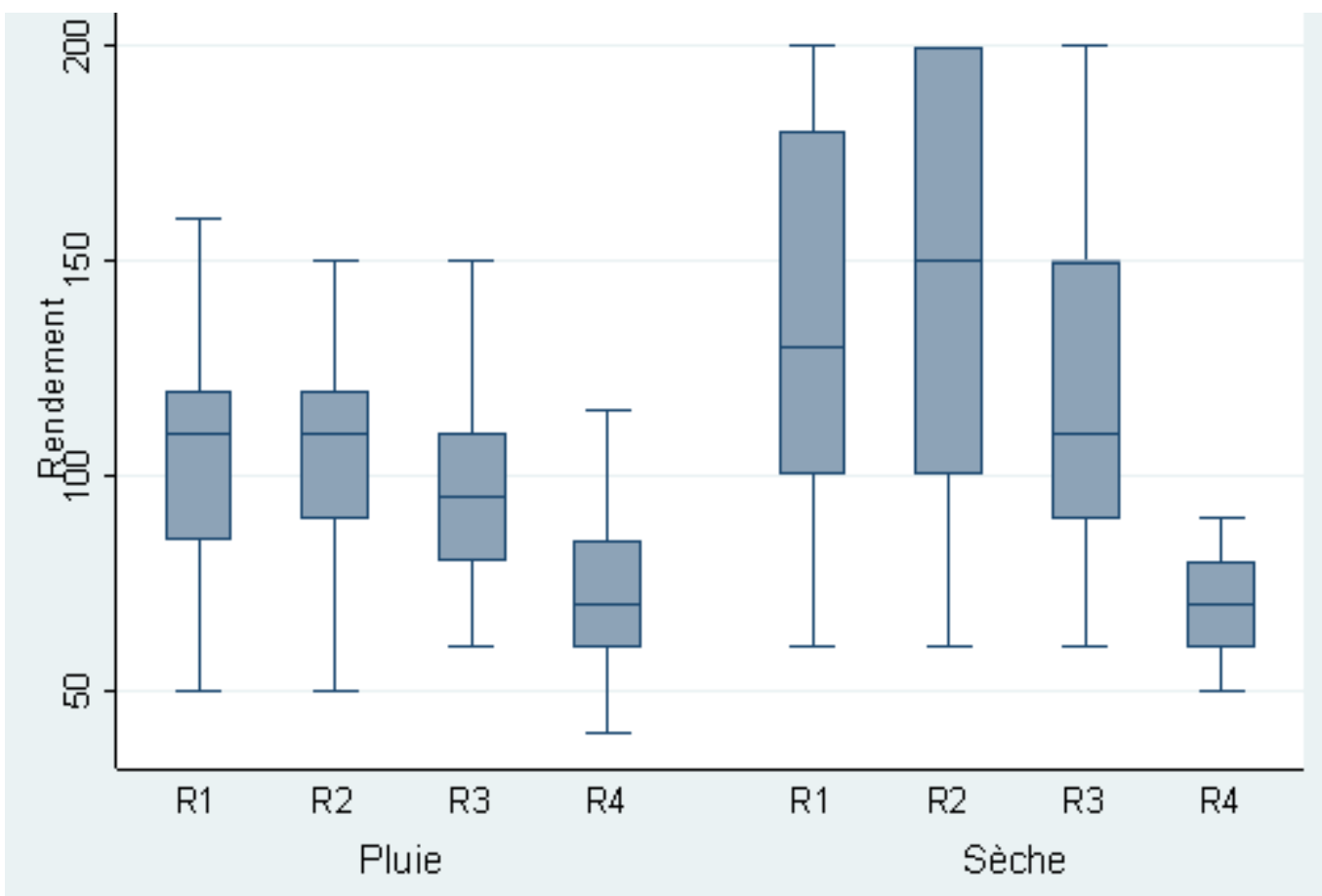

$\mathrm{R} 1$ : première récolte ; $\mathrm{R} 2$ : deuxième récolte ; $\mathrm{R} 3$ : troisième récolte ; $\mathrm{R} 4$ : quatrième récolte

Figure 4 : comparaison des rendements (gr) par saison avec la technique de l'étagère. 


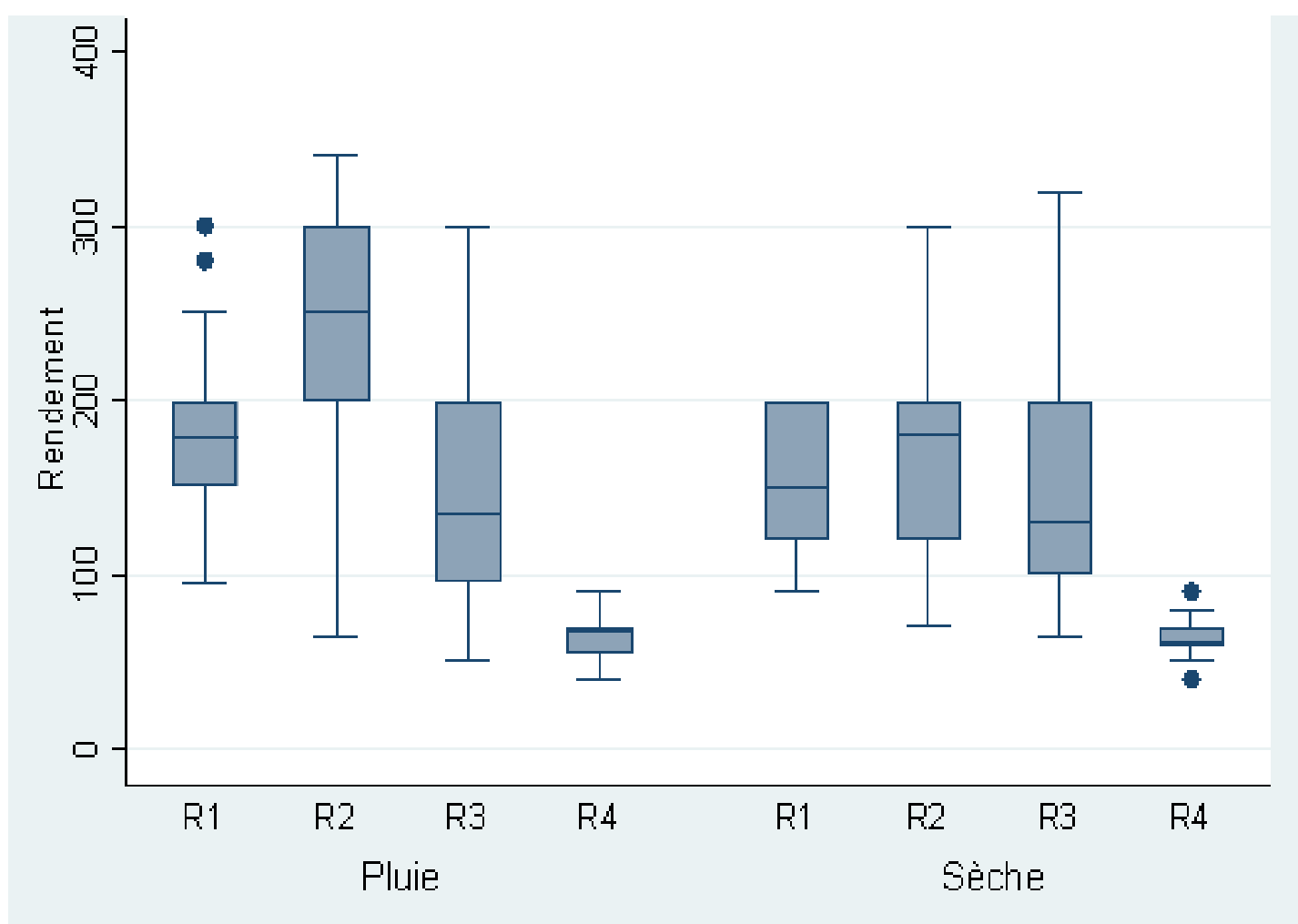

$\mathrm{R} 1$ : première récolte ; $\mathrm{R} 2$ : deuxième récolte $; \mathrm{R} 3$ : troisième récolte ; $\mathrm{R} 4$ : quatrième récolte

Figure 5 : comparaison des rendements (gr) par saison avec la technique du gobetage.

Tableau 2 : Analyse de variance des rendements globaux des champignons pour les deux techniques.

\begin{tabular}{lccccccc}
\hline T & Obs & Rendement & Moyenne & Variance & Ecart type & F statistic & P $\leq$ \\
\hline T0 & 30 & 11365 & 378,833 & 1561,523 & 39,516 & 351,7 & 0,0000 \\
T1 & 30 & 19160 & 638,667 & 4198,161 & 64,793 & & \\
Total & 60 & 30525 & 508,750 & 19995,44 & 141,405 & & \\
\hline
\end{tabular}

Légende :

T0 : technique de la champignonnière

T1 : technique du gobetage

\section{DISCUSSION}

La présente étude avait comme objectif de trouver une méthode de culture pouvant limiter les chutes de rendement de Pleurotus cystidiosus en saisons humides et chaudes. Elle se basait sur l'hypothèse selon laquelle la technique de gobetage pourrait être une solution appropriée à ce problème de chute de rendement du pleurote en saisons chaudes et humides. Cette différence n'a été constatée que pendant la période des fortes chaleurs. Les résultats de l'étude montrent que les moyennes des rendements pour le gobetage sont de 638,7 $\pm 64,8 \mathrm{~g}$ en saison des pluies et $531,3 \pm 94,03$ $\mathrm{g}$ en saison sèche et $378,8 \pm 39,5 \mathrm{~g}$ en saison de pluies et de $474,3 \mathrm{~g} \pm 50,1 \mathrm{~g}$ en saison sèche pour la culture à l'étagère.

La différence des moyennes constatée sur le rendement serait due à la technique de fructification du substrat utilisée. D'après les 
résultats de l'expérimentation, la technique de gobetage a donné un poids en champignon supérieur à celui de l'étagère de la champignonnière. Ces performances du Pleurote sont également confirmées par l'étude de Mondo et al. (2016) où les meilleures moyennes en termes de poids de Pleurotus oestratus ont été obtenues sur la technique de gobetage et alors que les moyennes les plus faibles ont été obtenues sur l'étagère.

En effet, nos résultats confirment, au seuil 0,05, l'existence d'une différence statistique $\mathrm{du}$ rendement du champignon produit d'un côté avec la technique du gobetage et de l'autre, avec celle de l'étagère. Le poids moyen de champignons obtenu par la technique de l'étagère est de $378,833 \pm 39,516$ g par kg de substrat contre $638,667 \pm 64,793 \mathrm{~g}$ pour chaque substrat de $1 \mathrm{~kg}$ avec la technique de gobetage.

Cela prouve à suffisance que, d'après l'hypothèse de départ, la technique de gobetage pourrait être une solution idoine à ce problème de chute de rendement pour la culture des champignons en général et du pleurote en particulier en périodes des fortes chaleurs (33,3 $\left.{ }^{\circ} \mathrm{C}\right)$. Cette température est supérieure à la température optimale pour une bonne croissance et fructification $\left(25^{\circ} \mathrm{C}\right.$ à $\left.30^{\circ} \mathrm{C}\right) . \mathrm{Ce}$ résultat serait relatif aux conditions favorables dans le substrat fournies par la technique de gobetage notamment l'humidité et la température, qui sont des facteurs physiques dont l'influence sur la croissance mycélienne et la fructification, est prépondérante (Enyard, 1975 ; Jandaik et al., 1995). CEil (2005) affirme que la couche du sol utilisée comme couverture de semences lors du gobetage procure non seulement des micro-organismes indispensables, mais joue également le rôle de régulateur de l'humidité qui, à son tour, induit une production des sporophores ayant un poids élevé par le mycélium. Cette humidité du sol et la présence des micro-organismes que procure le gobetage pourraient être à la base de l'augmentation de rendement.

\section{Conclusion}

A l'issue de cette étude, les résultats obtenus mènent aux conclusions suivantes : la technique de gobetage a donné le meilleur rendement en sporophore par rapport à la production sur l'étagère. De ce qui précède, la culture sur gobetage est à conseiller en myciculture. De nouvelles études devraient être menées notamment sur la technique du gobetage associée à différents substrats locaux afin d'améliorer davantage le rendement des pleurotes pour contribuer à la lutte contre l'insécurité alimentaire qui caractérise la sousrégion.

\section{CONTRIBUTIONS DES AUTEURS}

GN a fait l'expérimentation; SK et VM ont rédigé le manuscrit. Tous les auteurs ont lu et approuvé la version finale du manuscrit.

\section{CONFLITS D'INTERETS}

Les auteurs ne déclarent aucun conflit d'intérêts.

\section{REMERCIEMENTS}

Les auteurs remercient le Foyer Universitaire Saint Paul de Rhigini à Kinshasa pour le soutien matériel et financier. Ils remercient également les examinateurs pour leur contribution à l'amélioration du manuscrit.

\section{REFERENCES}

Bram VN, Janna DF. 2007. La Culture à petite échelle de champignons 2: Agaricus et Volvariella, Agrodok 41, Wageningen. Pays-Bas : Fondation Agromisa et CTA.

Eynard M. 1975.Influence de quelques facteurs physiques sur la fructification des champignons supérieurs Basidiomycètes (Etude bibliographique). Bulletin mensuel de la Société linnéenne de Lyon, 44e année, $n^{\circ}$, novembre. 330-336.

Jandaik CL, Goyal SP. 1995. Farm and farming of oyster mushroom (Pleurotus sp). In Mushroom Production Technology, Singh RP, Chaube HS (eds). G. B. Pant Univ. Agril. And Tech: Pantnagar, Uttarakhand ; 72-78.

Kirk PM, Cannon PF, Minter DW, Stalpers JA. 2008. Ainsworth and Bisby's Dictionary of the Fungi (10e édn). CAB Europe-UK: Wallingford. 
Loubelo E. 2012. Impact des produits forestiers non ligneux (PFNL) sur l'économie des ménages et la sécurité alimentaire : cas de la République du Congo. Economies et finances. Thèse de doctorat, Université Rennes 2, p.261.

Mondo J, Mubalama E, Mukengere B, Balezi A, Mushagalusa G. 2016. Effets des substrats à base de fanes de haricot et de feuilles de bananier sur la productivité des souches de Pleurotus ostreatus (P969 et HK51) sur étagère et gobetage. Vertigo, 1-9. DOI : 10.4000/vertigo.16899

Ndoye O, Awono A, Preece L, Toirambe B. 2007. Marchés des produits forestiers non ligneux dans les provinces de l'Equateur et de Bandundu: présentation d'une enquête de terrain. In Quel Avenir pour les Forêts de la République Démocratique du Congo ? Croizer C,
Trefon $\mathrm{T}$ (eds). Coopération Technique Belge (CTB) : Bruxelles ; 68-70.

Eil P. 1994. La Culture des Champignons. Edition Gret : Paris.

Eil P. 2005. La culture des Champignons à Petite Echelle: Pleurotes, Shiitakes et Auriculaires. Fondation Agromisa et CTA : Wageningen.

Pegler D, Piearce G. 1980. The edible Mushrooms of Zambia. Kew Bulletin, 35(3): 475-491. DOI: https://doi.org/10.2307/4110017

Verfaillie M. 1983. Mon Savoureux Petit Coin aux Champignons ; Manuel de Culture du Champignonniste Amateur. Edition Bruynell : Amsterdam.

Lelly J. 1987. Edible mushroom as a weapon against starvation. Mushroom Journal, 173: $170-171$. 